\title{
Research Trend on Aromatherapy for Korean Middle-aged Women
}

\author{
Hee-Jung Yong ${ }^{1,2}$, Hyun Hee Jang ${ }^{3}$, Sung Nae Lee ${ }^{4}$, Soo-Yeon Kim ${ }^{5}$, Young-Sam Kim ${ }^{6 *}$ \\ ${ }^{1}$ Department of Lecture, Beauty People Beauty School, Seongnam-si, Gyeonggi-do, Korea \\ ${ }^{2}$ Department of Bioengineering, Konkuk University, Seoul, Korea \\ ${ }^{3}$ School of Cosmetology, Kyungbok University, Namyangju-si, Gyeonggi-do, Korea \\ ${ }^{4}$ Department of Cosmetology, Kyung-In Women's University, Incheon, Korea \\ ${ }^{5}$ Department of Beauty Art, Doowon Technical University, Paju-si, Gyeonggi-do, Korea \\ ${ }^{6}$ Department of Image Industry, Graduate School of Engineering, Konkuk University, Seoul, Korea
}

"Corresponding author: Young-Sam Kim, Department of Image Industry, Graduate School of Engineering, Konkuk University, 120 Neungdong-ro, Gwangjin-gu, Seoul 05029, Korea

Tel.: +82 24503595

Email: gracehelen@konkuk.ac.k

\section{Received December 20, 2016}

Revised January 25, 2017

Accepted January 26, 2017

Published March 30, 2017

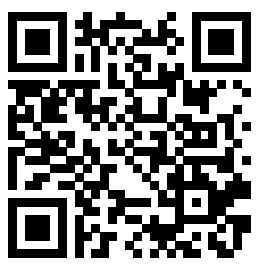

\begin{abstract}
This study analyzed aromatherapy researches in middle-aged women from thesis published in Korea $(\mathrm{N}=15)$ to understand its effects on psychological and physiological parameters in the subjects. Keywords used for searching were as follows: aromatherapy, aroma, hyanggi-yobeob, hyang-yobeob, and middle-aged women. The keywords were found on websites including the national assembly library and Korea education \& research information service. Collected data were analyzed by descriptive statistics. The results showed that sociopsychological variables such as stress, depression, and anxiety were higher than physiological variables. Also, most of the essential oils consist of three or four kinds of oils including lavender, bergamot, geranium, rose, and ylang ylang. The methods of application of aromatherapy included massage (33.3\%), inhalation (26.7\%), or a combination of massage and inhalation (20.0\%). The aroma massage method was found to be significantly effective in $100.0 \%$ of the studies and the inhalation method was effective in $75.0 \%$ of the studies. Such an analysis of previous studies is necessary to standardize the use of aroma oils in middle-aged women; however, it is necessary to verify these results through meta-analysis.
\end{abstract}

Keywords: Aromatherapy, Aroma, Hyanggi-yobeob, Hyang-yobeob, Middle-aged women

\section{Introduction}

최근 생활수준의 향상 및 과학과 의료의 발달로 인하여 인간의 평균수명이 연장되고(Kwon et al., 1996), 여성의 취업률 증가, 여 성의 자아에 대한 관심, 사회 심리적 여건의 변화 등으로 인해 중년 기에 대한 관심이 고조되고 있다(Park, 2002). 중년 여성은 청년기 와 노년기 사이의 성인여성을 말하며 중년기의 구분은 나라마다. 학자마다 상이한 견해를 제시하고 있는데, 대체적으로 국내 연구에 서는 40-59세를 기준으로 정하고 있다(Lim \& Kim, 2001). 중년 여 성은 신체적 노화와 더불어 폐경이라는 과정을 겪을 뿐만 아니라. 사회적, 심리적으로 자녀 양육에 대한 역할이 감소되면서 대내외적
으로 스트레스를 받게된다. 이러한 스트레스에 성공적으로 대처하 지 못하면 두통이나 피로, 불면증, 우울, 외로움, 실패감 등을 겪게 된다(Hyun, 2002; Jang, 2000; Washington, 1999).

최근 대체요법의 하나로 관심 받고 있는 아로마테라피는 식물의 꽃, 줄기, 잎, 열매, 뿌리, 레진 등에서 추출한 에센셜 오일을 이용 하여 호흡기나 피부를 통해 체내로 흡수되어 신체와 정신의 치유를 도모하는 치료방법을 말한다(Roh \& Park, 2009). 아로마테라피는 에센셜 오일에 함유된 화학성분의 분자량과 생화학적 특성에 따라 독특한 향과 치유성분들이 피부와 피부의 순환계, 후각계에 흡수 되어 뇌의 번연계를 통하여 심리적, 신체적 영향을 미치며 우울, 불 안과 스트레스 해소, 피로회복, 근육이완, 수면촉진, 면역증강 등 
의 효능을 나타낸다(Cerrato, 1998).

아로마테라피와 관련된 국내 연구는 1998년을 시작으로 석 - 박 사 학위 논문으로 처음 발표되기 시작하였으며, 2005년 이후에는 매년 연구가 꾸준히 지속되어 왔다(Jeon \& Woo, 2014). 초창기에 진행된 대부분의 아로마테라피 연구는 피부관리사들에 의해 피부 나 전신에 적용되어 신체적 및 정신적인 이완을 목적으로 많이 진 행되어 왔으며, 점차 아로마 에센셜 오일의 효과를 규명하는 임상 연구와 아로마테라피를 치료 목적으로 사용하는 의료인들의 효과 검증(Mo \& Song, 2007) 등으로 확대되어 현재는 여러 분야에서 다 양한 연구가 이루어지고 있다. 아로마테라피 적용 대상으로는 청소 년, 여성, 남성, 노인 등 다양했으나 여성이 주로 대상자로 선정되 었으며, 그 중에서도 중년 여성을 대상으로 한 실험 논문이 많았다.

아로마테라피를 적용한 연구들이 지속적으로 증가함에 따라 이 러한 연구들을 종합하여 아로마테라피의 연구의 경향을 제시해주고 반복연구로 인한 소모적인 연구를 지양하며, 후속 연구의 방향과 전 략을 제시할 필요성이 대두되었다(Kim, 2004). 따라서 본 연구에서 는 국내에서 발표된 학위논문 중에서 중년여성을 대상으로 한 아로 마테라피의 실험논문을 분석하여 연구동향을 파악하고 향후 중년여 성을 위한 아로마테라피 개발의 기초 자료를 제공하고자 한다.

\section{Methods}

\section{1. 연구설계}

본 연구는 2000년부터 2016년까지 국내 학위논문에 발표된 아 로마테라피 실험논문 중에서 중년여성을 대상으로 한 논문의 연구 경향과 적용결과를 분석한 문헌고찰 연구이다.

\section{2. 연구대상 논문 선정}

국내에서 실시된 아로마테라피 실험논문 중에서 중년여성을 대 상으로 한 연구를 찾기 위해서 검색사이트는 국회도서관, 한국교육 학술정보원에 등록된 논문을 자료로 이용하였다. 검색어는 아로마 테라피, 아로마, 향기요법, 향요법, 중년여성을 사용하여 학위논문 22 편을 수집하였다. 이 중 다른 요법과 병행한 논문 6 편, 실험논문 이 아닌 논문 1 편을 제외하여 최종 15 편의 논문이 선정되었다.

\section{3. 연구대상 논문의 분석 기준}

본 연구 분석에 선정된 논문에서 사용한 기준을 근거로 하여 분 석 기준을 정하고 요목화하여 자료분석용 양식을 만들어 정리하였 으며, 세부 내용은 다음과 같다.

\section{1) 발표연도와 전공분야}

논문의 발표연도는 5 년 단위로 구분하였고, 전공분야는 간호학, 대체의학, 보건학, 의학, 미용학으로 구분하였다.

2) 연구설계와 대상자의 특성

연구설계는 비동등성 대조군 전후설계, 비동등성 대조군 전후시 차설계, 단일집단 전후설계, 교차 실험설계로 구분하였다. 그 밖에 표본 크기, 표본 집단 수를 구분하여 분석하였다.

\section{3) 종속변수}

연구대상 논문에서 사용된 종속변수는 사회심리적 변수 측정, 생리적 변수 자가보고 측정 및 생리적 변수 직접 측정 등 3 가지 영 역으로 구분하여 분석하였다. 사회심리 변수 측정은 스트레스, 우 울, 불안을 측정하였고, 생리적 변수 자가보고 측정은 수면, 피로, 통증, 두통, 갱년기증상, 식욕을 측정하였으며, 생리적 변수 직접 측정은 코티졸, 혈압, 면역반응, 심박변이도, 카테콜아민, 정신안 정과 정신각성을 측정하였다.

\section{4) 아로마테라피의 적용방법}

사용한 에센셜 오일의 개수와 종류를 분석하였고, 적용방법에 따라 마사지, 흡입, 마사지와 흡입 병행, 도포와 흡입 병행, 마사지 와 도포 병행으로 구분하여 분석하였다.

5) 아로마테라피 적용에 따른 효과 유무

아로마테라피 적용에 따른 효과 유무는 각 연구논문에서 제시한 $p$ 값으로 분석하였다.

\section{4. 자료 분석}

자료 분석을 위하여 빈도와 백분율을 구하였다.

Table 1. Years of publication and types of thesis

\begin{tabular}{ccccccc}
\hline \multirow{2}{*}{ Year } & $\begin{array}{c}\text { Number of } \\
\text { publication }\end{array}$ & Nursing & $\begin{array}{c}\text { Alternative } \\
\text { medicine }\end{array}$ & Health & Medicine & Cosmetology \\
\cline { 3 - 7 } $2000-2004$ & 1 & 1 & - & - & - & - \\
\hline $2005-2009$ & 6 & 3 & 3 & - & - & - \\
\hline $2010-2014$ & 5 & 2 & - & 1 & - & - \\
\hline $2015-2016$ & 3 & 1 & 1 & $1(6.7)$ & $0(0.0)$ & $3(20.0)$ \\
\hline Total $(\%)$ & $15(100.0)$ & $7(46.7)$ & $4(26.7)$ & & & - \\
\hline
\end{tabular}




\section{Results}

\section{1. 발표연도별, 연구설계별 연구현황}

연구대상논문 15 편을 연도별로 분석한 결과, 2000년에서 2004 년에 발표된 논문은 1편(6.7\%), 2005년에서 2009년에 발표된 논문 은 6편(40.0\%), 2010년에서 2014년에 발표된 논문은 5편(33.3\%), 2015년 이후에 발표된 논문은 3편(20.0\%)이었다(Table 1). 전공분 야는 간호학이 7 편(46.7\%), 대체의학이 4편(26.7\%), 보건학이 1편
(6.7\%), 의학이 0편(0.0\%), 미용학이 3편(20.0\%)이었다.

사용된 연구설계를 살펴보면, 비동등성 대조군 전후설계가 12 편(80.0\%)으로 가장 많았고, 비동등성 대조군 전후시차설계가 1 편(6.7\%), 단일집단 전후설계가 1편(6.7\%), 교차 실험설계가 1편 (6.7\%)이었다(Table 2). 표본의 크기는 40명 이상이 5편(33.3\%), 30-39명이 3편(20.0\%), 20-29명이 3편(20.0\%), 10-19명이 4편 (26.7\%)이었으며, 표본 집단 수는 두 집단이 10편(66.7\%), 세 집단 4 편(26.7\%), 단일 집단 1 편(6.7\%)이었다.

Table 2. Characteristics of articles analyzed in the study

\begin{tabular}{|c|c|c|}
\hline Variables & Categories & $N(\%)$ \\
\hline \multirow{4}{*}{ Research design } & Nonequivalence control group pretest-posttest & $12(80.0)$ \\
\hline & Nonequivalence control group non-synchronized & $1(6.7)$ \\
\hline & One-group pretest-posttest & $1(6.7)$ \\
\hline & Cross experimental & $1(6.7)$ \\
\hline \multirow{4}{*}{ Sample size of group } & $10-19$ & $4(26.7)$ \\
\hline & $20-29$ & $3(20.0)$ \\
\hline & 30-39 & $3(20.0)$ \\
\hline & $40 \leq$ & $5(33.3)$ \\
\hline \multirow{3}{*}{ Group } & One & $1(6.7)$ \\
\hline & Two & $10(66.7)$ \\
\hline & Three & $4(26.7)$ \\
\hline
\end{tabular}

Table 3. Types and results of dependent variables

\begin{tabular}{|c|c|c|}
\hline Variables & Categories & $\mathrm{N}(\%)$ \\
\hline \multirow{4}{*}{$\begin{array}{l}\text { Measurement of } \\
\text { sociopsychological variable } \\
\text { by self-report }\end{array}$} & Stress & $8(53.3)$ \\
\hline & Depression & $4(26.7)$ \\
\hline & Anxiety & $2(13.3)$ \\
\hline & Subtotal & $14(45.2)$ \\
\hline \multirow{7}{*}{$\begin{array}{l}\text { Measurement of } \\
\text { physiological variable } \\
\text { by self-report }\end{array}$} & Sleep & $3(20.0)$ \\
\hline & Fatigue & $1(6.7)$ \\
\hline & Pain & $1(6.7)$ \\
\hline & Headache & $1(6.7)$ \\
\hline & Climacteric symptoms & $2(13.3)$ \\
\hline & Appetite & $1(6.7)$ \\
\hline & Subtotal & $9(29.0)$ \\
\hline \multirow{9}{*}{$\begin{array}{l}\text { Measurement of } \\
\text { physiological variable } \\
\text { by direct measure }\end{array}$} & Cortisol & $1(6.7)$ \\
\hline & Blood pressure & $2(13.3)$ \\
\hline & Immune responses & $1(6.7)$ \\
\hline & Heart rate & $1(6.7)$ \\
\hline & Catecholamines & $1(6.7)$ \\
\hline & Psychologic relaxation & $1(6.7)$ \\
\hline & Psychologic stimulation & $1(6.7)$ \\
\hline & Subtotal & $8(25.8)$ \\
\hline & Total (\%) & 31 (100.0) \\
\hline
\end{tabular}




\section{2. 종속변수 측정별 연구현황}

종속변수는 사회심리 변수 측정, 생리적 변수 자가보고 측정, 생 리적 변수 직접 측정의 3 가지 영역으로 나눌 수 있는데, 사회심리 변수 측정은 스트레스, 우울, 불안 등과 같은 사회심리학적 변수를 사회심리학적 측정도구나 설문지를 이용하여 자가보고 형식으로 측정한 것이다. 그리고 생리적 변수 자가보고 측정은 수면, 피로, 통증, 두통, 갱년기증상, 식욕 등과 같이 직접 측정이 어려운 생리 적 변수를 생리적 측정도구나 설문지를 이용하여 자가보고 형식으 로 측정한 것이다. 생리적 직접 측정은 코티졸, 혈압, 면역반응, 심 박변이도, 카테콜아민, 정신안정과 정신각성 등과 같이 직접 측정 이 가능한 생리적 변수를 혈액 분석장비, 혈압계, 심전도 측정장비, 뇌파측정기 등과 같은 기구를 이용하여 측정한 것이다.

본 연구에서의 종속변수로는 스트레스, 우울, 불안, 수면, 피로, 통증, 두통, 갱년기증상, 식욕, 코티졸, 혈압, 면역반응, 심박변이 도, 카테콜아민, 정신안정, 정신각성 총 16 개로, 전 영역을 아울렀 을 때 이 중에서 가장 많이 측정된 변수는 스트레스 8편(53.3\%)이 었고, 우울이 4편(26.7\%), 수면이 3편(20.0\%), 불안과 갱년기증상, 혈압이 각각 2편씩(13.3\%)이었다(Table 3).

각각의 영역별로는 사회심리 변수 측정의 경우, 총 14 건(45.2\%) 을 측정하였으며, 그 중에서 스트레스를 측정한 논문이 8편으로 가 장 많았다. 다음으로 우울을 측정한 논문이 4편, 불안을 측정한 논 문이 2 편이었다. 생리적 변수를 자가보고한 상태로 측정한 경우는 9건(29.0\%)을 측정하였으며, 그 중에서 수면을 측정한 논문이 3 편 으로 가장 많았고, 다음이 갱년기증상을 측정한 논문이 2편이었다. 생리적 변수 직접 측정은 8 건(25.8\%)을 측정하였으며, 그 중에서 혈압을 측정한 논문이 2 편으로 가장 많았다.

\section{3. 중재방법 연구현황}

1) 적용한 에센셜 오일

연구에 사용한 에센셜 오일의 수는 3가지 오일을 사용한 논문이 7 편(46.7\%), 4 가지 이상의 오일을 사용한 논문이 5 편(33.3\%), 2 가 지 오일을 사용한 논문이 2편(13.3\%), 1가지 오일을 사용한 논문이 1 편(6.7\%)이었다(Table 4). 15 편의 논문에서 라벤더는 13회(26.5\%) 로 가장 많이 사용한 오일이었으며 제라늄, 버가못, 로즈, 일랑일 랑은 각 4 회(8.2\%), 오렌지, 페퍼민트는 각 3회(6.1\%), 네놀리, 로즈 마리는 각 2회(4.1\%) 사용하였다. 이외에도 샌달우드, 사이프러스, 바 질, 마조람, 그레이프푸룻, 파인, 티트리, 카모마일, 유칼립투스, 클라 리세이지 등의 오일을 다양하게 사용하였다. 라벤더는 스트레스와 우 울의 각 분야의 논문에서 사용빈도가 가장 높은 오일로 나타났다.

\section{2) 아로마테라피 적용 방법 및 효과}

15 편의 논문 중 마사지만을 적용한 연구는 5 편(33.3\%)으로 등마 사지(2편), 발마사지(1편), 두피마사지(1편), 전신마사지(1편)의 방 법으로 적용하였다. 흡입법만을 적용한 연구는 4편(26.7\%)으로 오 일 원액을 티슈, 향기패드를 사용하여 향기를 흡입하였다(Table 5). 두 가지 방법을 병행 적용한 연구는 6 편(40.0\%)으로 마사지와 흡입 (3편), 도포와 흡입(2편), 마사지와 도포(1편)이었다.

적용방법에 따른 효과를 보면 아로마 마사지를 적용한 연구에서 는 5 편 중 5 편(100.0\%)이 유의한 효과가 있다고 보고하였고, 흡입 법을 이용한 연구는 4편 중 3 편(75.0\%)이 유의한 효과가 있는 것으 로, 1 편은 부분적 유의한 효과가 있는 것으로 되어있다. 두 가지 방 법을 병행 적용한 연구에서는 마사지와 흡입 3편 중 3편(100.0\%), 도포와 흡입 2편 중 2편(100.0\%) 모두 유의한 효과가 있다고 되어

\section{Table 4. Number of blended essential oils and types of essential oil}

\begin{tabular}{|c|c|c|}
\hline Variables & Categories & $\mathrm{N}(\%)$ \\
\hline \multirow{4}{*}{$\begin{array}{l}\text { Number of blended } \\
\text { essential oil }\end{array}$} & 1 type & $1(6.7)$ \\
\hline & 2 types & $2(13.3)$ \\
\hline & 3 types & $7(46.7)$ \\
\hline & More than 4 types & $5(33.3)$ \\
\hline \multirow{11}{*}{ Types of essential oil } & Lavender & $13(26.5)$ \\
\hline & Bergamot & $4(8.2)$ \\
\hline & Geranium & $4(8.2)$ \\
\hline & Rose & $4(8.2)$ \\
\hline & Ylang ylang & $4(8.2)$ \\
\hline & Orange & $3(6.1)$ \\
\hline & Peppermint & $3(6.1)$ \\
\hline & Neroli & $2(4.1)$ \\
\hline & Rosemary & $2(4.1)$ \\
\hline & Others ${ }^{1)}$ & $10(20.4)$ \\
\hline & Total (\%) & $49(100.0)$ \\
\hline
\end{tabular}

${ }^{1)}$ Others: sandalwood, cypress, basil, marjoram, grapefruit, pine, tea tree, chamomile, eucalyptus, clary sage. 
있다. 마사지와 도포 1편 중 1편(100.0\%)이 부분적 유의한 효과가 있다고 되어있다.

\section{Discussion}

중년기는 발달 과정상에서 보면 생리적, 심리적, 신체적, 사회 적으로 다양한 변화를 겪는 시기이다. 중년 여성들은 이러한 변화 들을 경험하면서 자신을 수용하고 성숙해지기도 하지만 이러한 변 화에 잘 적용하지 못하면 위기, 고립, 위축 등 정서적 문제를 일 으키고 심하면 우울과 같은 정서장애를 경험하기도 한다(Chun \& Kwon, 1994).

최근 인간에게 내재되어 있는 자연치유력을 향상시켜 우리 신체 스스로 치료할 수 있도록 돕는 대체의학에 대한 관심과 요구가 증대 되고 있다. 대체의학 중의 하나인 아로마테라피는 현대의학에서 사 용하는 약물 치료보다 부작용이 적어 비교적 안전하고 간편하게 사 용할 수 있다(Welsh, 1997). 또한, 아로마테라피는 면역기능의 개선 과 신경의 자극 또는 이완을 통한 두통, 소화 장애, 식욕부진 등의 증 상에 사용할 수 있고 정서적으로 감정을 안정 혹은 흥분시키는 기 능이 있어 불안, 공포, 우울, 분노, 불면 등의 증상을 완화시켜 준다 (Tobin, 1995).

중년여성을 대상으로 한 아로마테라피의 효과를 검증한 학위논 문이 2000년 이전에는 한편도 없었으나 2016년까지 22편에 이를 정도로 중년여성을 대상으로 한 아로마테라피의 연구가 증가하고 있음을 알 수 있다. 전공분야는 간호학 전공이 7편(46.7\%)으로 가 장 많았고, 그 외 대체의학, 미용학, 보건학 전공 등으로 다양한 분 야에서 아로마테라피에 관심을 가지고 있는 것으로 사료되며, 간호 학 전공자들의 경우 아로마테라피를 이용한 연구를 통해 실무에 활 용하려는 노력을 하고 있는 것으로 볼 수 있다.

연구 설계별 가장 많이 이용된 설계는 비동등성 대조군 전후설 계(12편)로, 이 설계가 가장 많은 이유는 연구의 특성상 무작위배정 의 어려움 때문에 동질성을 확보하여, 실험처치 효과를 확인하기 위해 통제된 상태로 연구하고자 하는 시도 때문인 것으로 볼 수 있다.
종속변수 측정현황을 보면 스트레스, 우울, 불안 등과 같은 사회 심리학적 변수를 사회심리학적 측정도구나 설문지를 이용하여 자 가보고 형식으로 측정한 사회심리 변수 측정 방법을 가장 많이 적 용하여 측정하였다. 특히 사회심리 변수 측정에서는 스트레스(8 편)가 가장 많았고 다음이 우울(4편)과 불안(2편) 순으로 나타났다. 직접 측정이 어려운 생리적 변수를 생리적 측정도구나 설문지를 이 용하여 자가보고 형식으로 측정한 생리적 변수 자가보고 측정에서 는 수면(3편)이 가장 많았고, 직접 측정이 가능한 생리적 변수를 다 양한 기구를 이용하여 측정한 생리적 변수 직접 측정은 혈압(2편) 이 가장 많았다. 또한 심리적 변수 측정이 생리적 변수의 측정보다 높게 나타났다. 이것은 심리적 변화의 시기인 중년여성을 대상으로 한 연구 논문이기 때문으로 사료된다.

아로마 오일 중재방법 적용현황을 보면 적용한 아로마 오일의 수 는 3 가지와 4 가지 이상의 오일을 사용한 논문이 각각 7편(46.7\%), 5 편(33.3\%)으로 많은 논문이 아로마 오일을 블랜딩하여 사용하였다. 이는 아로마 오일을 단독으로 사용하는 것보다 두 가지 이상의 오 일을 블랜딩하여 사용할 때 시너지 효과를 얻을 수 있다는 근거(Oh et al., 2002)를 뒷받침하는 결과로 사료된다.

15 편의 논문에 적용된 아로마 오일 중 라벤더 오일은 13 회(26.5\%) 로 가장 많이 이용되었다. 라벤더 오일은 진통, 항우울, 항염, 항균, 해독, 이완, 진정작용 등을 하는 오일로 감정에 균형을 잡아주고, 우울감, 스트레스, 불면증, 두통, 긴장을 이완시켜 삶의 질 향상에 효과가 있다(Hirokawa et al., 2012). 또한 인체에 유해작용이 거 의 없고 여러 개의 아로마 오일을 블랜딩할 때 향을 중화하는 작용 을 하므로 쉽고 안전하게 사용할 수 있다는 장점이 있다(Oh et al., 2002). 이러한 라벤더의 특성으로 본 연구에서도 스트레스, 우울, 불안에 사용한 연구가 많았다.

제라늄, 일랑일랑, 로즈 오일은 에스트로겐 호르몬 분비를 증가 시키거나 에스트로겐 성분과 유사한 성분을 함유하고 있어 폐경기 관련 증상에 효과적으로 사용할 수 있다(Seo \& Park, 2003). 또한 버가못 오일은 정신적인 측면에 크게 작용하는 오일로 억압된 감정 과 막연한 불안감에서 마음을 해방시켜준다.

불면, 흥분, 침울, 걱정, 정서불안, 우울상태(quoted in Lim,

\section{Table 5. Classification according to the methods of intervention}

\begin{tabular}{|c|c|c|c|c|}
\hline \multirow{2}{*}{ Types of intervention } & \multirow{2}{*}{$\mathrm{N}(\%)$} & \multicolumn{3}{|c|}{ Effects } \\
\hline & & Positive effects (\%) & Partial positive effects (\%) & No effects (\%) \\
\hline Massage & $5(33.3)$ & $5(100.0)$ & - & - \\
\hline Inhalation & $4(26.7)$ & $3(75.0)$ & $1(25.0)$ & - \\
\hline Massage+Inhalation & $3(20.0)$ & $3(100.0)$ & - & - \\
\hline Application+Inhalation & $2(13.3)$ & $2(100.0)$ & - & - \\
\hline Massage+Application & $1(6.7)$ & $-1)$ & $1(100.0)$ & - \\
\hline Total (\%) & 15 (100.0) & $13(86.7)$ & 2 (13.3) & $0(0.0)$ \\
\hline
\end{tabular}

${ }^{1)}$ Not occur. 
2013)에 탁월한 효과가 있어 라벤더와 함께 많이 사용되었다.

아로마 오일 적용방법은 마사지가 주를 이루고 있었으며, 흡입 법보다는 마사지를 이용한 연구에서 긍정적인 효과가 더 많이 보고 되었다. 아로마 오일을 이용하여 마사지를 병행하게 되면 마사지를 통해 아로마 오일이 피부로 빠르게 흡수되어 혈류를 타고 전신으로 순환하여 화학적 반응이 이루어지고 마사지의 자극이 신체적, 심리 적 이완효과를 가져오게 되므로 동시에 두 가지 요법의 효과를 얻 을 수 있다(Choi, 2006)는 근거 때문으로 사료된다. 그러나 많은 논 문에서 적용한 아로마 오일의 종류가 다양했고, 아로마 오일의 혼합 비율에 약간씩 차이를 보여 아로마 오일에 따라 차이가 있는지 또는 최상의 배합비율이 어떤것인지와 대상자에 따른 반복연구가 이루어 져 아로마테라피 적용의 일반화를 할 수 있도록 해야할 것이다.

적용방법에 따른 효과성을 살펴보면 아로마 마사지를 이용한 연 구에서는 5 편 모두 유의한 효과가 있었고, 흡입법을 적용한 연구 에서는 4 편 중 3 편은 유의한 효과가 있었으나 1 편은 부분적 유의한 효과가 있었다. 이는 오일의 종류나 혼합비율에 따라 결과가 다르 게 나온것으로 보인다. 본 논문에서는 연구마다 사용한 오일의 종 류, 적용방법, 적용기간이 동일하지 않아 연구를 비교, 해석하는데 제한점이 있었고, 향후 신뢰성 있는 객관적인 결과를 위해서는 반 복 연구가 필요할 것으로 생각된다.

\section{Conclusion}

중년여성을 대상으로 한 아로마테라피는 스트레스, 우울, 불안 등의 심리적 부분에 대한 효과를 주로 다루고 있으며, 상당히 효과 적이라는 결론이 도출되었다. 또한 통증이나 수면에도 긍정적인 연 구결과들이 나타났으나 이러한 연구들은 주로 주관적인 대상자들 의 반응에 근거하고 있었고, 생리적 지표와 같은 객관적인 기준을 이용한 연구는 매우 적었다. 추후 중년여성을 대상으로 한 아로마 테라피의 실무에서 활용할 수 있도록 조금 더 객관적인 지표를 병 행하여 이러한 변수들의 효과를 평가하는 반복 연구를 진행할 필요 가 있고, 연구가 보다 많아지게 되면 메타분석을 이용하여 그 효과 를 검증할 것을 제언한다.

이 외에도 아로마테라피의 적용기간이나 방법 등을 다양화하여 보다 효과적인 아로마 오일의 사용방법을 표준화하는 것이 필요하 며, 중재방법에 따른 효과의 차이를 비교하는 연구도 진행될 필요가 있다.

\section{References}

Cerrato PL. Aromatherapy: is it for real? RN, 61: 51-52, 1998. Choi IR. Effects of aromatherapy massage on pain, physical function, sleep disturbance and depression in elderly women with osteoarthritis. Korean Journal of Women Health Nursing, 12: 168-176, 2006.

Chun CJ, Kwon YE. A study of the relationship between self concept and self-reported climacteric symptoms of middle-aged women. Korean Journal of Adult Nursing, 6: 48-57, 1994.

Hirokawa K, Nishimoto T, Taniguchi T. Effects of lavender aroma on sleep quality in healthy Japanese students. Perceptual and Motor Skills, 114: 111-122, 2012.

Hyun KS. The effect of the Dan-jun breathing exercise program on pulmonary function and psychological health of women in midlife. Journal of Korean Academy of Nursing, 32: 459-469, 2002.

Jang HJ. The psychological effect of hand and arm massage on middle-aged women. Journal of Korean Academy of Nursing, 30: 1389-1399, 2000.

Jeon YA, Woo N. A meta-analysis of obesity management effects of aromatherapy use. Asian Journal of Beauty and Cosmetology, 12: 275-281, 2014.

Kim YO. Analysis of nursing studies on hardiness published in Korea. Korean Journal of Adult Nursing, 16: 27-36, 2004.

Kwon SH, Kim YJ, Moon GN, Kim IS, Park GJ, Park CH, Bai JY, Song AR, You JH, Chung ES, et al. An analysis of the relationship between menopausal symptoms and depression. Korean Journal of Women Health Nursing, 2: 235-245, 1996.

Lim HY, Kim KS. The effects of social support network on the life satisfaction of married middle-aged women. Family and Environment Research, 39: 189-203, 2001.

Lim JH. Aromatherapy textbook (easy to learn). lasobook, Seoul, p138, 2013. (Wada Al, 2008.)

Mo JH, Song MR. A study on the current status of use and satisfaction in aromatherapy. Journal of Environmental and Sanitary Engineering, 22: 45-54, 2007.

Oh HG, Lee WM, Son HS. Aromatherapy handbook: perfect guide for specialist. Yangmoon Publishers, Seoul, pp4142, 2002.

Park GJ. Factors influencing the meaning of life for middleaged women. Korean Journal of Women Health Nursing, 8: 232-243, 2002.

Roh KH, Park HA. A meta-analysis of the effects of aromatherapy on psychological variables in nursing. Journal of Korean 
Academy of Community Health Nursing, 20: 113-122, 2009.

Seo HG, Park GS. A study on the effects of aroma inhalation method using clarysage essential oil on stress in middleaged women. Korean Journal of Women Health Nursing, 9: 70-79, 2003.

Tobin P. Aromatherapy and its application in the management of people with dementia. The Lamp, 52: 34, 1995.
Washington O. Effects of cognitive and experiential group therapy on self-efficacy and perceptions of employability of chemically dependent women. Issues in Mental Health Nursing, 20: 181-198, 1999.

Welsh C. Touch with oils: a pertinent part of holistic hospice care. American Journal of Hospice and Palliative Medicine, 14: 42-44, 1997. 


\section{국문초록}

\section{중년여성을 대상으로 한 아로마테라피 실험연구 동향분석}

용희정 ${ }^{1,2}$, 장현희 ${ }^{3}$, 이성내 ${ }^{4}$, 김수연 ${ }^{5}$, 김영삼 ${ }^{6 *}$

${ }^{1}$ 아름다운사람들 뷰티스쿨 강사부, 경기도 성남시, 한국

${ }^{2}$ 건국대학교 생물공학과, 서울, 한국

${ }^{3}$ 경복대학교 예술학부, 경기도 남양주시, 한국

${ }^{4}$ 경인여자대학교 피부미용과, 인천, 한국

${ }^{5}$ 두원공과대학교 뷰티아트과, 경기도 파주시, 한국

${ }^{6}$ 건국대학교 산업대학원 이미지산업학과, 서울, 한국

본 논문은 중년여성을 대상을 한 아로마테라피에 관한 국내 실험논문을 분석하여 연구동향을 파악하고 향후 중년여성을 위한 아로마 테라피 중재 개발의 기초 자료로 제공하고자 한다. 아로마테라피, 아로마, 향기요법, 향요법, 중년여성의 키워드를 사용하여 국회도 서관, 한국교육학술정보원 사이트에서 검색된 논문 중 실험논문 15 편을 분석하였다. 수집된 자료는 분석기준에 따라 정리하여, 빈도 및 백분율로 자료를 나타내었다. 논문을 분석한 결과, 스트레스, 우울, 불안과 같은 심리적 변수의 측정이 생리적 변수의 측정보다 높 게 나타났다. 적용한 아로마 오일의 수는 3-4종류의 오일을 블랜딩한 경우가 가장 많았고, 라벤더, 버가못, 제라늄, 로즈, 일랑일랑 등 의 오일을 가장 많이 사용하였다. 적용방법으로는 마사지가 $33.3 \%$ 로 가장 많았고, 흡입법이 $26.7 \%$, 마사지와 흡입을 병행한 연구가 $20.0 \%$ 이었다. 적용방법에 따른 효과를 보면 아로마 마사지를 적용한 연구에서는 모두 유의한 효과가 있었고, 흡입법을 적용한 연구에 서는 $75.0 \%$ 가 유의한 효과가 있었다. 중년여성을 대상으로 한 아로마 오일의 사용방법을 표준화하는 반복연구의 축적이 필요하며, 다 양한 메타분석을 통해 그 효과를 검증할 필요가 있다.

핵심어: 아로마테라피, 아로마, 향기요법, 향요법, 중년여성

\section{참고문헌}

권숙희, 김영자, 문길남, 김인순, 박금자, 박춘화, 배정이, 송애리, 여정희, 정은순, 등. 중년 여성의 갱년기 증상과 우울에 관한 연

구. 여성건강간호학회지, 2: 235-245, 1996.

김영옥. 강인성에 대한 국내 간호논문 분석. 성인간호학회지, 16: 27-36, 2004.

노국희, 박현애. 아로마테라피 간호중재의 정신심리적 효과 메타분석. 지역사회간호학회지, 20: 113-122, 2009.

모정희, 송미라. 아로마테라피의 활용실태와 만족에 관한 연구. 환경위생공학, 22: 45-54, 2007.

박금자. 중년여성의 삶의 의미와 영향요인. 여성건강간호학회지, 8: 232-243, 2002.

서혜경, 박경숙. 클라리세이지(Clarysage) 에센셜 오일을 이용한 향기 흡입법이 중년여성의 스트레스 감소에 미치는 효과. 여성

건강간호학회지, 9: 70-79, 2003.

오홍근, 이우만, 손현수. 아로마테라피 핸드북: 전문인을 위한 완벽 가이드. 양문, 서울, pp41-42, 2002.

임정희. (누구나 쉽게 배우는) 아로마테라피 교과서. 이아소, 서울, p138, 2013. (화전문서, 2008.)

전연아, 우나리야. 아로마테라피를 이용한 비만관리효과의 메타분석. 아시안뷰티화장품학술지, 12: 275-281, 2014.

전정자, 권영은. 중년기 여성의 자아개념과 갱년기 증상과의 관계연구. 성인간호학회지, 6: 48-57, 1994.

최인령. 향 요법 마사지가 골관절염 여성 노인의 통증, 신체기능, 수면장애 및 우울에 미치는 효과. 여성건강간호학회지, 12 :

168-176, 2006. 


\section{中文摘要}

\section{韩国中年女性为对象的芳香疗法研究动向分析}

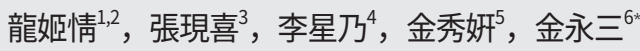

美丽人美容学校讲师部, 京畿道城南市, 韩国

2建国大学生物工学科, 首尔, 韩国

3京福大学美容艺术系, 京畿道南杨州市, 韩国

敬仁女子大学皮肤美容科，仁川，韩国

5斗源工科大学美容艺术科, 京畿道坡州市, 韩国

建国大学产业大学院影像产业学科, 首尔, 韩国

本研究旨在分析对韩国学位论文中以中年女性为对象进行的芳香疗法实验论文, 掌握其研究动向, 并为中年女性的芳香 疗法开发而提供基础数据。在韩国教育和研究信息服务，国民议会图书馆等网站上对芳香、香气、香气疗法、香疗法和 中年女性等关键词进行搜索。在搜索的论文, 对其中15篇论文进行分析。收集的资料按分析标准整理, 采用频率及百分 率进行分析。结果表明, 如压力、抑郁、焦虑等心理因素均高于生理变量。大多数精油是由三至四种精油组合而成, 其 中使用最多的是薰衣草、佛手柑、天竺葵、玫瑰、依兰依兰等精油。适用方法中，按摩占33.3\%，吸入法占26.7\%，按摩 和吸入并行的研究占 $20.0 \%$ 。根据不同适用方法的有效性研究结果, 适用芳香疗法的研究都具有统计意义的效果, 适用吸 入法的研究中只有 $75.0 \%$ 具有统计意义的效果。因此, 有必要通过反复研究来规范中年女性香薰油的使用方法, 并通过各 种meta分析来验证其使用效果。

关键词: 芳香疗法，芳香，香气疗法，香疗法，中年女性 